\title{
\$⿳亠口冋 Accomplished Teaching, Learning and Schools (ATLAS)
}

\section{Abstract}

The Accomplished Teaching, Learning and Schools (ATLAS) database is a valuable teaching tool that takes some of the mystery out of the National Board for Professional Teaching Standards certification process, and provides pre-service and novice in-service teachers with a repository of best practices to use as models while they develop their own teaching practices. The database was specifically designed for Colleges and Schools of Education in higher education, state departments of education, and school districts to support the professional development of pre-service and in-service teachers. The content of the database is dependent on the subscriber's geographic location, but includes over 1,000 cases aligned to the National Board for Professional Teaching Standards (NBPTS) and its Five Core Propositions and six other collections including edTPA, InTASC, Next Generation Science Standards (NGSS), TeachingWorks High-Leverage Practices, Common Core State Standards (CCSS) in English Language Arts/ Literacy and Math, Deeper Learning Competencies, and the College, Career, and Civic Life (C3) Framework for Social Studies State Standards. All cases include a 15 to 20 minute video of an accomplished teacher facilitating a lesson in his or her own classroom, written commentary analyzing the planning, instructional context, and effectiveness of the lesson, and additional background information and instructional materials to provide context for users to understand each case. All case materials were included in portfolios submitted by National Board Certified Teachers during their National Board candidacy. Despite its restrictive contract provisions, ATLAS's content, intuitive user interface, powerful advanced search feature, and interactive tools make it a highly recommended resource for Colleges and Schools of Education within higher education, state departments of education, and K-12 school districts.

\section{Pricing Options}

A standard one-year subscription to ATLAS costs $\$ 3,500$ and covers up to 250 users. ATLAS also offers tiered pricing, which can cover 100 to 5,000 users with a declining cost per user. ATLAS recently began offering a pricing tier of $\$ 750$ for smaller programs and organizations which will cover up to 100 users. For schools and organizations with smaller user groups, ATLAS does actively encourage organizations to form a consortium. This would allow smaller organizations to subscribe to ATLAS, and help lower the overall cost for all members of the consortium. Typically, these consortiums have formed through existing organizations such as a regional service center or a state affil- iation of colleges of education, similar to a state chapter of the American Association of Colleges for Teacher Education. Given these multiple pricing variables potential customers are encouraged to contact ATLAS for specific pricing before considering a subscription.

\section{Product Description}

Accomplished Teaching, Learning and Schools (ATLAS) is a Webbased library of case studies showing National Board Certified Teachers at work in their classrooms. The database's audience is comprised of three main groups. One group is colleges or schools of education within higher education, specifically faculty who work with pre-service teachers in teaching methods courses or students who are preparing for, or are in the midst of, teaching internships. The other two groups work within K-12 education, such as state departments of education and K-12 school districts where site-based administrators or professional development directors work with early career in-service teachers. The intent of this resource is to support pre-service and novice in-service teachers with examples of the art, science, and social impact of teaching through model teacher behavior.

Entries in ATLAS are referred to as cases. Each case was submitted by PreK-12 educators as a part of their portfolio during their National Board Certification candidacy and was assessed as accomplished practice using the National Board's well-established certification process. A 15 to 20 minute video of the teacher facilitating a lesson in his or her own classroom accompanies each case, as well as written commentary explaining the instructional context of the lesson, the planning involved, and a critical analysis and reflection of what went well and what could be done differently in the future. Copies of the instructional materials used during the lesson will provide users much needed context, as does the presence of background materials. These background materials describe the National Board Certification process, why candidates for certification submitted the specific video, commentary, and instructional materials as part of their portfolio, and the National Board's Five Core Propositions for Teaching and the discipline standards addressed by the case.

All 1,044 cases within ATLAS are indexed to what are called collections. The collections include the National Board's Five Core Propositions for Teaching and Discipline Standards, which is the only collection to include all 1,044 cases within the database. Select cases are also indexed to other common frameworks including: edTPA (182 cases); the TeachingWorks High-Leverage Practices (128); CCSS for English Language Arts/Literacy (78); CCSS Mathematics (23); 
Deeper Learning Competencies (98); C3 Framework for Social Studies State Standards (107); InTASC (141); and the NGSS (29). ATLAS has indicated indexing cases to these standards and frameworks is an ongoing process, and more cases already within ATLAS will be indexed to these collections over time.

Differentiating ATLAS from most databases are the two defined user groups: group leaders, and teachers and teacher candidates. In addition to these two groups, there is generally one designated contact within the organization given the administrative ability to manage access to the database based on the total number of users allowed per the terms and conditions. These administrators invite group leaders to join the organization's group. Group leaders are typically faculty within a College of Education, mentor teachers, or school district professional developers. Group leaders are given administrative authority to create their own groups and invite teachers or teacher candidates to join. In effect, a faculty member who, for example, is teaching three sections of the same methods course in a given semester can create a group for each class, and invite his or her students to join the corresponding group. Aside from this basic administrative authority, the only difference between a group leader and a teacher or teacher candidate is that group leaders can download case commentaries to view them offline. Both groups have the ability to conduct searches, create personal and group folders, save cases to personal and/or group folders, and annotate and apply framework tags to a case video, commentary, and instructional materials.

The minimum Internet browser requirements are Internet Explorer 9.0, Firefox 15, Chrome 28.0.1500, and Safari 7. ATLAS strongly recommends using the latest or newest version of these Internet browsers for the best possible user experience. ATLAS can also be accessed through mobile devices.

\section{Critical Evaluation}

\section{CONTENT}

Each individual case includes a 15 to 20 minute video, the teacher's written commentary, background information on the NBPTS candidacy process for the specific area the teacher applied, and instructional materials used in the lesson, if applicable. At this point in time, the overall size of the database, at approximately 1,044 cases, is adequate. All cases are current, as the oldest cases within the database were submitted by National Board candidates in 2011. ATLAS has given every indication that the database will grow in size based on its users' needs even as older, out of date cases no longer used by subscribers are weeded out. Intent on keeping the database current, ATLAS plans on updating the content based on current trends in K-12 education such as changing standards, and adapting to the expectations and needs of its user base.

Because every educator at the center of each case has earned their National Board certification, it is difficult to argue against the overall quality of the content within each case. As a former high school social studies teacher, the author enjoyed reading through the teachers' written commentaries which are, by default, displayed immediately underneath each case's video. Experienced educators who read the commentaries may be hard pressed not to think, "That makes perfect sense," or, "I wish I had thought of that while I was still in the classroom." The time and effort each of these accomplished teachers put, not only in their reflective commentaries, but in the art and craft of pedagogy is abundantly clear. There are, however, a few specific features of ATLAS's content that need to be discussed.
The content in each video is second to none, and each provides wonderful examples of accomplished teachers in action. The video display and controls are similar to that of a YouTube video, which most users should be able to pick up quickly. Video quality can vary from video to video but not enough to affect viewing. Audio quality, on the other hand, can vary dramatically from video to video. Users must remember that these videos are not professionally done and are more akin to home videos. As a result, many videos have at least some ambient noise, but it rarely affects the overall video quality. In most cases, audio quality is good enough to distinguish what is being said and by whom, but there are exceptions. For example, in a case video involving a school counselor creating an academic intervention plan with a fourth grade student, the counselor can be heard loud and clear, but the student is so soft-spoken he is difficult to understand. Another example is a video where the class is broken up into groups so students can collaborate on a project. Instances like this can lead to too much background noise, making it difficult to understand the teacher and students who should be the focus of video. These issues could be easily solved by turning on the closed captioning, but not all videos have it nor are transcripts available. A random sampling of 100 cases showed approximately $15 \%$ of the videos have closed captioning available, but ATLAS is dedicated to extending closed captioning to every video in its library to comply with Americans with Disabilities Act (ADA) guidelines.

Cases also include a Background Information tab to the immediate right of the Commentary tab, and it provides much needed context about a teacher's National Board Certification candidacy, general information about what a case is, and the National Board's Five Core Propositions and Standards. Additional links to specific pages on the NBPTS.org and BoardCertifiedTeacher.org Web sites are included if users would like additional information. The rightmost tab is the Instructional Material tab. There is a brief description of what instructional materials are, along with a Download Instructional Materials link. Clicking the link automatically opens a new tab in the user's browser and displays the materials in PDF format, which is easy to save locally. Most of the instructional materials seem to be scanned copies of the original documents. A common outcome of scanning documents is the gray shadow that can appear on the background of the copy. Fortunately, this does not affect the readability of typed text, but it must be noted that handwritten notes or drawings can be difficult to read at times.

Concerns about this resource should not be about the total number of cases nor their content. While every case is indexed to the NBPTS Five Core Propositions and Standards, only about one-third of all cases are aligned to at least one of the eight other collections mentioned above. ATLAS has indicated that indexing each case is a complicated and time-consuming endeavor, but they intend to get the job done right the first time even if it means the database grows at a slow, yet methodical, pace. On the other hand, the tags associated with each case are an outstanding resource to have. Each case is tagged with a subject area, topics within the broader subject, and grade level. Individual tags also serve as a link to all other cases with the same tag. Directly underneath these tags are the framework standards the case is indexed to. Each framework standard provides a link which expands the standard to show its definition to provide context and the reason why that standard is related to the case. Links to specific times of the video, areas of the commentary, and instructional materials that directly relate to the standard are also conveniently placed and easy to use. 
Most subjects, especially core subjects such as Mathematics, English/ Language Arts, Science, and Social Studies, have more than enough cases to sift through to find useful examples to use, while other subjects lack an adequate amount of cases. Electives such as Health, Music, Career and Technical Education, and World Languages may not have enough cases for group leaders to choose from, and subjects for non-classroom teachers, Library Media, and School Counseling face the same issue. In addition, not all topics within a subject area have cases. For example, despite Literacy \& English/Language Arts having the highest number of cases with 313 , six of the eighteen topics within the subject area have five cases or fewer including two which have zero. This is not uncommon, as other subject areas have the majority of their cases indexed to handful of topic areas while other topics have few, if any cases.

It would also be nice to see a more even distribution of content across grade levels. English/Language Arts may provide the most even distribution. This subject area includes, on average, the same amount of content from Pre-Kindergarten (PreK) through 12th grade. Perhaps understandably, PreK has the lowest number of cases with eight, but all other grade levels vary between 17 and 39 cases with an average of 26. One extreme can be seen in Music where almost half (16) of the 40 cases are indexed to the 9-12 grade levels, with a general decline in the number of total cases per grade as the grade level drops.

\section{INTERFACE}

The user interface is sleek and clean, and eliminates any unnecessary wording and visuals that could cause distractions. While the video, commentary, and instructional materials naturally change from case to case, all else in the page's layout remains the same. The left-hand side of the page displays the case's title, case number, and a brief abstract followed by its subject area, topic, and grade level tags. Directly underneath are the framework tags which can be viewed by scrolling down the page or using a dropdown menu to filter the results by a specific framework. The search pages have the same design and are consistent. Search results take up the right two-thirds of the screen while limiters are on the left. Each limiter is divided by headings, Subject \& Topic, Grade Level, and Framework, and can be expanded to see all limiters available. A link to the advanced search is always conveniently located directly underneath the Framework heading.

\section{SEARCH}

There are multiple ways to jump into searching for cases. A simple search box is located at the top of every page, as is a link to the advanced search. Users can enter ATLAS through the collection level from the main page to search within a single collection or add additional cases via the limiters on the left. Users may also filter search results within selected frameworks by title, relevance, date, or popularity and can save cases, or entire searches, to personal or group folders directly from the search results. Unfortunately, ATLAS can be difficult to search if you do not know exactly what you are looking for. The standard search feature is best used when users have a specific case number they need to look up. Even if users have a specific standard to search for, typing "CCSS.ELA.SL1" into the search box, for example, will return zero results. Using the standard's exact title, Conversations and Collaborative Discussion will only produce one unrelated result. Of course, as with any other database, search terms matter. A search for "Harper Lee" results in the retrieval of two cases, but searching for "To Kill A Mockingbird" will produce another three cases. Instead of the standard search feature, users will be better off browsing for the framework collection and standard they need to find, or going directly to the advanced search page. Potential customers and their patrons need to remember that ATLAS was not designed for this purpose, and, if the search is used in this way, it will only cause headaches. Although, it is easy to envision pre-service and novice inservice teachers using ATLAS to search for individual cases by topic to use as models in the development of lessons for their own classrooms.

Users are better served browsing the database to find what they are looking for by entering the database through the collection level from the main page, and using the limiters mentioned earlier. This allows the user to browse the collection by topic or grade level, but also switch to another framework with ease. A link to the advanced search is always underneath these limiters, and users are also given the option to search within their results.

The easiest way to search ATLAS is the advanced search feature. The advanced search page is user-friendly and compact. The page clearly marks each category with a heading box and shows a handful of search options underneath. A down arrow on the right-hand side of the heading box will notify a user of additional options within that category. An intuitive click of the arrow will expand the category to show every option available. Users can simply check boxes to choose their search criteria as they scroll down the page. Category headings on the advanced search page include Grade Level, the Five Core Propositions, Framework, Subject \& Topic, Instructional Strategies, School Type, School Setting, Student Characteristics, and Certificate Area. It is these categories and their contents that should make users defer to the advanced search as their default choice. Users looking for science cases using active listening techniques in suburban high schools can quickly complete their search within seconds using the advanced search rather than using the trial and error approach of the standard search. Of course, as with most other databases, the more focused users make their search through the selection of more terms the fewer results will be returned.

\section{TOOLS}

ATLAS offers a number of convenient and easy-to-use tools for its users. Users should be able to intuitively pick up how to save cases to folders, take notes, and search the database, but a Help Links button resides on the top of every page. The Help Links page gives group leaders, teachers, and teacher candidates their own Quick Start Guide to help them through the process step-by-step along with a frequently asked questions document. ATLAS's tools and features are so intuitive, the only other help option given - or even needed-is the "?" icon situated above a case's commentary. Hover the mouse over the icon to learn how to add comments to the commentary.

Users can create folders to save search results and/or specific cases as well as add notes to a case's written commentary, video, and instructional materials. Videos have a "+ Add Note" button in the top right corner, and, once clicked, users can type a note, add the starting and end time for a specific section of the video, and choose a specific framework tag. Tagging a note with a framework can be as simple as choosing one of the eight collections within ATLAS, or as detailed as choosing a framework, framework (subject) area and framework tag (specific standard). Users can also designate the note to be personal and seen only by them, or they can choose to share the note with their instructor/group leader or other members of their group. Notes added to the commentary and instructional materials offer the same 


\section{Accomplished Teaching, Learning and Schools (ATLAS) Review Scores Composite: $\star \star \star 1 / 2$}

The maximum number of stars in each category is 5 .

\section{Content: $\quad \star \star \star \star 1 / 2$}

The content in this database is extremely valuable, and easy to manipulate into useful teaching tools that will provide support for the development of pre-service and novice in-service teachers. A more even distribution of cases in non-core subjects and topics within current subject areas is needed.

\section{User Interface/Searchability: $\quad \star \star \star \star$}

The interface is intuitive and easy to use. Better indexing would make the standard search feature more accurate, but the ability to efficiently browse the collections and usability of the advanced search feature more than make up for its limitations. A higher score is warranted once closed captioning is added to all videos.

\section{Pricing:}

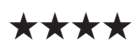

Overall, the pricing for such a unique resource is not unreasonable for larger organizations within higher education or state departments of education. Smaller organizations can form a consortium to ease any potential financial burden.

\section{Contract Options: $\quad \star 1 / 2$}

In order to protect identities and confidential data within the database, contract provisions are very restrictive and include the restriction of fair use rights. The contract is specifically written for Colleges or Schools of Education in higher education, state departments of education and K-12 school districts, not academic libraries.

options, and, once a note is made, an additional Notes tab is added to the case. The saving and sharing options help build a platform where group members can easily see, search, and view other group members' saved cases and notes. This only enhances ATLAS's effectiveness as a professional development tool because it allows groups to collaborate, share what they have learned, and build a network of learners among group members.

\section{Contract Provisions}

Despite the fact that all identifiable information of the teachers and students are taken out of the cases, ATLAS goes to great lengths in its contract to protect the identity of the teachers and students that could be visually identifiable in the case material. One way ATLAS does this is by tailoring the database's content based on a subscribing organization's geographic location. For example, if a school district in or around the New York City metro area has a subscription, ATLAS will modify which cases are included in the database so users will not be able to use or even see cases submitted by Board Certified teachers in New York City schools. Although, case materials submitted by Board Certified teachers in closely adjoining states and similar metropolitan areas from other parts of the country will be available. With this in mind, it is entirely possible subscribers in different parts of the country will have access to a completely different set of cases.

The other way ATLAS protects the identity of the teachers and students shown in its database is through its contract provisions. The content can only be used for administrative users' own professional growth and development or in the development and preparation of courses and/or instructional materials to provide examples of accomplished teaching practice. The permitted use of the licensed content is extremely limited and restricts fair use rights to protect confidential data, and is why ATLAS does not currently offer an IP-based site license for its subscribers. This is why designated administrative users are responsible for creating an authorized users list and inviting individual users to access ATLAS content.

This last point is beyond the scope of an academic library, and is a stark reminder that ATLAS was specifically designed and created to be used by Schools or Colleges of Education in higher education, state departments of education, or K-12 school districts as a professional development tool. It is an advantage for organizations to have the ability to take user licenses from, say, a student who dropped a class or a teacher who moved on to another district, and easily transfer that user license to another student or new hire. Unfortunately, this aspect would only be a burden for librarians. Liaisons, subject specialists, or collection development librarians are not in the position to coordinate and keep track of defined user groups for the databases to which it subscribes by constructing a list of authorized users, updating the list as needed, or creating a new list every semester. Academic libraries would also be hard pressed to agree to the restricted access described by the terms and conditions as well as the policing of the database's use and its users. Because libraries would be expected to provide access to the campus community as a whole, enforcing many of the contract's provisions would be impossible on such a large scale.

ATLAS has noted that more and more academic libraries have shown interest in subscribing to the database, and is willing to consult with 


\section{Contact Information}

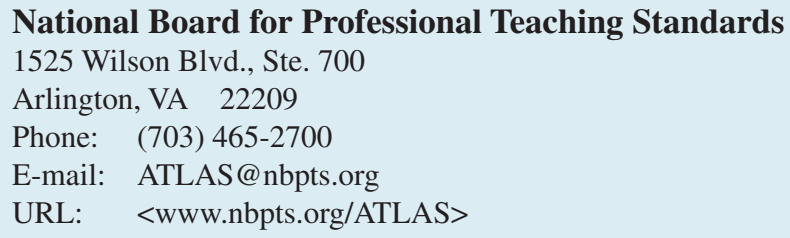

the profession to determine if a suitable contract could be constructed to meet everyone's needs. At this time, however, the wording of the current contract will make it difficult for an academic library to subscribe to ATLAS. Despite this, it cannot be stressed strongly enough that information professionals should still feel comfortable recommending ATLAS as a resource for the database's target audiences who will have an easier time complying with the contract's provisions.

\section{Authentication}

Authentication can be achieved with the individual user's e-mail address and a generic password. The password is generated by an administrative user and can easily be changed after accepting the initial invitation from their group leader.

\section{About the Author}

Daniel Zuberbier is the Education \& Instructional Technology Librarian at East Carolina University's Joyner Library. He earned his Bachelor of Arts in History from the University of Wisconsin-Madison in 2005 and his MLIS from the University of Wisconsin-Milwaukee in 2013. Prior to working at East Carolina University, he was a high school Social Studies teacher and School Library Media Specialist in Arizona and an Intervention Specialist for at-risk students in Michigan.

\section{Subscribe TO The Charleston Advisor Today!}

\section{The Charleston Advisor: Critical Reviews of Web Products for Information Professionals}

\section{Over 500 Reviews Now Included}

- Libraries pay less than $\$ .60$ per review

- Publishers pay less than $\$ 1.00$ per review

\section{How Much Are You Spending?}

- Web Database and Quarterly Print are now available at the low price of $\$ \mathbf{2 9 5 . 0 0}$ for libraries; $\mathbf{\$ 4 9 5 . 0 0}$ for all others.

\section{ORDER YOUR SUBSCRIPTION TODAY.}

Order on the Web: www.charlestonco.com

\section{YES! Enter my Subscription for One Year.}

Name:

Title:

Organization:

Address:

City/State/Zip:

Phone:Fax:

E-Mail:

$\square$ YES. I am interested in being a Reviewer.

6180 E. Warren Ave., Denver, CO 80222

Phone: (303) 282-9706 Fax: (303)282-9743 